Fountain Journal of Natural and Applied Sciences: 2015; 4(1): 01 - 09

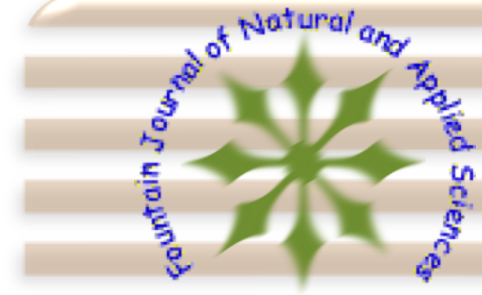

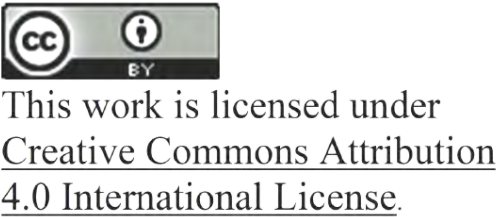

DOI: $10.53704 /$ fujnas.v4i1.51

A publication of College of Natural and Applied Sciences, Fountain University, Osogbo, Nigeria

Journal homepage: www.fountainjournals.com

ISSN: 2354-337X (Online), 2350-1863 (Print)

\title{
Comparative Assessment of Antibacterial Efficacy of four popular hand sanitizers sold in Nigeria
}

\author{
Odebisi-Omokanye M. B. ${ }^{1}$, Ahmed El-Imam A. M. ${ }^{1}$, Arshad S. O. ${ }^{1}$, Oke M. A. ${ }^{1,2^{\star}}$ \\ ${ }^{1}$ Department of Microbiology, Faculty of Life Sciences, University of Ilorin, P.M. B. 1515, Ilorin, Nigeria. \\ ${ }^{2}$ Microbiology Division, Institute of Biological Sciences, Faculty of Science, University of Malaya, 50603, Kuala Lumpur, Malaysia.
}

\begin{abstract}
Despite the increase in popularity of hand sanitizers (HS) in Nigeria, there is a dearth of literature on the efficacies of these products. This study assessed the efficacies of four popular brands of HS in Nigeria against some clinically important bacterial pathogens. Using the well variant of the agar dilution method to determine antimicrobial susceptibility and the broth dilution method to determine minimum inhibitory concentration, the activities of the HS (HSF, HSM, HDT, and HSK) were evaluated against Staphylococcus aureus, Pseudomonas aeruginosa, Escherichia coli, and Klebsiella pneumonia. Each of the products displayed varying activities against the test organisms. HSM had the highest inhibitory effect against all the test organisms, while HSF was the least effective. S. aureus was the most susceptible organism, with the highest susceptibility to HSM $(12.0 \mathrm{~mm})$. P. aeruginosa was the most resistant organism, with the highest resistance to HSM $(9.0 \mathrm{~mm})$. Each of the HS was bacteriostatic against all of the test bacteria and none displayed bactericidal activity. HSM and HDT reduced the mean colonyforming unit (cfu) counts of bacteria on the hands of subjects by $72 \%$ and $62 \%$, respectively. A onetailed t-test showed that HSM was more effective than HDT in this regard. None of the products could reduce bacterial counts by $99.9 \%$, as the manufacturers claim. Such claims need to be verified to ensure that these products contain the correct quantities of active ingredients, and sellers need to store such products according to the manufacturers' instructions.
\end{abstract}

Keywords: Hand hygiene, Hand sanitizer, Nosocomial infection, Community-acquired infection, Antimicrobials

\section{Introduction}

The hands play an important role in the transmission of infections in the home, community, hospitals and in various other settings. Many studies have linked the hands of individuals (patients, care givers and ordinary folks) with the spread of infections in various environments (Knittle et al., 1975; Mortimer Jr et al., 1962; WHO, 2006). Furthermore, the hands are the most implicated in relation to the transmission of gastro-intestinal, respiratory and skin infections.

*Corresponding author: +2348035818938

Email address: oke.ma@unilorin.edu.ng 
Hand hygiene has been demonstrated to reduce infections in hospital and non-hospital settings (Bloomfield et al., 2007; Gagne et al., 2010; Sheehan et al., 2007; Talaat et al., 2011), and the Centers for Disease Control and Prevention (CDC) and World Health Organisation (WHO) have thus promoted hand hygiene as the single most important measure in combating healthcare-associated infections (Boyce and Pittet, 2002; WHO, 2006).

Despite numerous campaigns and expert opinions encouraging the adoption of hand hygiene, compliance has been low among individuals and healthcare workers. Some of the reasons for noncompliance with hand hygiene guidelines include skin irritation caused by hand hygiene agents, inaccessibility of hand hygiene agents, usage of gloves, forgetfulness, high workload, insufficient time for hand hygiene, and prioritizing patients' needs over hand hygiene (WHO, 2006).

A common barrier to achieving hand hygiene by conventional hand washing is the fact that rigorous hand-washing involves scrubbing both hands with soap for about 20 seconds, rinsing for another 30 seconds and lastly drying. This puts off harried health-workers and ordinary people from regular hand hygiene. Hand sanitizers have been suggested as one of the ways to overcome this among other barriers to hand hygiene compliance. Hand sanitizers are preparations (liquid, gel or foam) containing alcohol or non-alcohol based active ingredients which are applied to the hands in order to reduce the number of viable microorganisms on them. However, the $C D C$ only recommends the use of alcohol-based hand sanitizers (Boyce and Pittet, 2002). Hand sanitizers are preferred over conventional hand washing with soap and water in terms of compliance because they are more effective in antimicrobial action, they are more convenient, and they are gentler on the skin and require less time for hand washing (Jumaa, 2005).

Numerous studies have reported the effectiveness of alcohol-based hand sanitizers in increasing hand hygiene compliance and reducing rates of infections in hospitals and community settinas. In a studv desianed to determine the effect of the introduction of accessible alcoholbased sanitizer intervention on hand hygiene compliance by health care workers in the medical intensive care unit of an hospital, Bischoff et al. (2000) found that significantly higher level of compliance (23\% before patient contact and $48 \%$ after patient contact) was observed with the provision of one sanitizer with dispenser per bed as compared to baseline compliance of $10 \%$ before patient care and $22 \%$ after patient care before the intervention. Similarly, Sakamoto et al. (2010) found that alcohol-based hand sanitizer use was the only factor that significantly contributed to the reduction and eventual eradication of methicillin-resistant Staphylococcus aureus (MRSA) incidences in a neonatal intensive care unit.

In spite of the reports of the effectiveness of hand sanitizers in reducing infections, there is still a need to verify the efficacy of individual products. This need is underscored by recent warnings by the United States Food and Drugs Administration (USFDA) in relation to false and exaggerated claims by some manufacturers (FDA, 2011) and some studies that demonstrated poor efficacy of some products against common infectious agents (Liu et al., 2010; Oke et al., 2013; Reynolds et al., 2006).

Furthermore, most guidelines and literature relating to hand hygiene are based on medical settings in developed countries (Jumaa, 2005). Given the poor access to proper sanitation and health facilities in developing countries like Nigeria, more research need to be conducted to assess conventional and alternative methods of hand hygiene with a view to reducing the high morbidity and mortality resulting from nosocomial and community-acquired infections in such countries. The use of hand sanitizers was not popular in Nigeria prior to the recent Ebola episode that claimed many lives. In fact, there were very few brands in the market before the Ebola episode and the government regulatory agency, NAFDAC (National Agency for Food and Drugs Administration and Control), only recently registered more brands. Despite the increasing popularity of these hand sanitizers in the 
Nigerian market, there is no specific guideline for their administration and application. Literature on the evaluation of their efficacies is also scanty.

This study was therefore conducted to evaluate the antibacterial efficacy of four popular brands of hand sanitizers in sold in Nigeria.

\section{Materials and Methods \\ Test organisms}

Staphylococcus aureus, Pseudomonas aeruginosa, Escherichia coli and Klebsiella spp. obtained from the culture collection of the Department of Microbiology, University of Ilorin, were used as test organisms in this study. These four bacteria are commonly implicated in cases of nosocomial and community-acquired infections (Montravers et al., 2009; Rosenthal et al., 2008). This informed the choice of their selection

\section{Hand sanitizers (HS)}

Four popular brands of waterless, gel form, alcohol-based HS products commonly sold and used in Nigeria were chosen for the study. The products were selected based on our interactions with consumers and our observation at different retail outlets. Each of the products was stored as recommended by its manufacturer and they were used well before their expiration dates.

Table 1 shows the composition of the products (with codes representing each brand).

\section{Standardization of test organisms}

The test bacteria were standardized following the method recommended by the Clinical and Laboratory Standards Institute (formerly known as National Committee for Clinical Laboratory Standards)(CLSI, 2006). McFarland 0.5 turbidity standard was prepared by mixing 0.5 $\mathrm{ml}$ of $1.175 \% \mathrm{w} / \mathrm{v}$ barium chloride dihydrate $\left(\mathrm{BaCl}_{2} .2 \mathrm{H}_{2} \mathrm{O}\right)$ with $99.5 \mathrm{ml}$ of $1 \% \mathrm{v} / \mathrm{v}$ sulphuric acid $\left(\mathrm{H}_{2} \mathrm{SO}_{4}\right)$. The mixture was shaken vigorously to achieve a fine suspension which was then dispensed into a test tube. The accuracy of the standard was verified using a spectrophotometer. Absorbance of $0.5 \mathrm{McF}$ arland turbidity standard at $625 \mathrm{~nm}$ is $0.08-.013$. The turbidity standard was dispensed into test tubes with the same diameter and height as those used in preparing the inoculum suspensions of the test bacteria. They were stored in the dark at room temperature until when needed.

To prepare the inoculum standards, 3-5 colonies of the bacteria were suspended in a tube containing sterile normal saline. Each tube was compared to that of the turbidity standard and the turbidity was adjusted appropriately by adding either more sterile saline or more bacteria. Cultures with turbidity adjusted to $0.5 \mathrm{McF}$ arland standard usually contain approximately 1 to $2 \times$ $10^{8} \mathrm{cfu} / \mathrm{ml}$ cells (CLSI, 2006).

Table 1: Hand sanitizers used in this study and their compositions.

\begin{tabular}{|c|c|}
\hline Product & Composition \\
\hline HSF & $\begin{array}{l}\text { 62\% Ethyl Alcohol, Aqua, Glycerin, Carbomer, Triethanolamine, Tocopheryl mynstafe, parfum, Limonene, } \\
\text { Linalool, Geraniol, Cironellal, Citral. }\end{array}$ \\
\hline HSM & $\begin{array}{c}62 \% \text { Ethyl alcohol, water, isopropyl alcohol, carbomer, tocophenyl acetate, glycerin, propylene glycol, } \\
\text { isopropyl myristate, fragrance. }\end{array}$ \\
\hline HDT & $\begin{array}{c}\text { Alcohol denat, aqua, PEG/PPG-17/16 copolymers, Acrylate/c10-30 Akyl Acrylate cross polymer, } \\
\text { Tetrahydroxyl propyl Ethylenediamine, parfum, and limonene. }\end{array}$ \\
\hline HSK & $\begin{array}{c}62 \% \text { Isopropyl Alcohol, water, glycerin, propylene glycol, fragrance, triethanolamine, carbopol } 940, \\
\text { acetate isopropyl myristate. }\end{array}$ \\
\hline
\end{tabular}


Susceptibility of test bacteria to hand sanitizers

The well-variant of the agar diffusion method described by Valgas et al. (2007) was modified and adopted in assessing the susceptibility of the test organisms to the sanitizers. Each test organism was seeded onto the surface of a sterile Mueller Hinton agar plate using a sterile cotton swab. The cotton swab was dipped into a tube of standardized inoculum and was spread evenly over the surface of the agar in order to have confluent growth of the organism. $A$ sterile $4 \mathrm{~mm}$ cork borer was used to create three wells in the agar for each test organism. Next 100 $\mu$ of an undiluted sample of each HS was introduced into each well. One of the wells was filled with the same volume of sterile distilled water to serve as negative control and a commercial disinfectant (Dettol ${ }^{\circledR}$ ) was used as positive control. All the plates were incubated at $37{ }^{\circ} \mathrm{C}$ for 24 hours in an upright position. The diameter of the zone of inhibition around each well was measured to the nearest millimetre along the two axes of the well at $90^{\circ}$ to each other and the mean of the two readings was recorded.

\section{Minimum inhibitory concentration (MIC) determination}

Minimum inhibitory concentration is the lowest concentration of an antimicrobial agent that completely inhibits the growth of a test organism as seen by the unaided eye (CLSI, 2006). To determine the MIC, increasing concentrations ( $5 \%-100 \%$ with $5 \%$ intervals) of each HS were prepared in $9 \mathrm{ml}$ tubes of sterile nutrient broth. Exactly $100 \mu$ of each standardized test organism was then introduced into each tube of HS. A tube containing only nutrient broth and bacteria without sanitizer served as negative control while another tube containing just the sanitizer and broth without bacteria served as positive control. Each tube was incubated for 18 hours and then examined for visible growth or turbidity. The concentration of the HS in the tube in which no visible growth was observed when compared with the controls was taken as the MIC.
Minimum bactericidal concentration (MBC) determination

Minimum bactericidal concentration is the lowest concentration of an antimicrobial that can kill the test organism (Cheesbrough, 2006). To determine the MBC for each HS, samples from the test tubes used in MIC test that showed no visible growth after the period of incubation were inoculated on sterile nutrient agar plates (which had no antimicrobial incorporated) in them using sterile swab sticks. The plates were incubated at $37^{\circ} \mathrm{C}$ for 18-24 hours and were then observed for growth. The concentration at which absence of growth was observed (bactericidal activity) was taken as the $M B C$.

\section{In vivo reduction of viable bacteria counts on hands of subjects}

Two products which displayed highest activity against test bacteria in the susceptibility test were further evaluated for their efficacy in reducing baseline bacterial counts on hands of subjects. Five individuals were selected for each product and verbal informed consent was obtained from each subject prior to the conduct of the experiment. Subjects did not apply any antimicrobial substance to their hands prior to the experiment. Sterile nutrient agar plates were divided into two halves with one half labelled BF (before) and the other labelled AF (after). Subjects were asked to gently make an impression on the surface of the BF side of the agar plate with the three unwashed fingers. After this, $3 \mathrm{ml}$ of the HS was then applied to the hands and then rubbed thoroughly on the palms, fingers, and the back of the hands until the hands became completely dry. Subjects were then asked to repeat the finger impression on the AF part of the plate. This was done by all subjects. The plates were incubated at $37{ }^{\circ} \mathrm{C}$ for 24 hours and the numbers of colonies were counted. The percentage cfu reduction was calculated as follows:

$\% c f u$ reduction $=\frac{c f u \text { count on } B F \text { section }-c f u \text { count on } A F \text { section }}{c f u \text { count on } B F \text { section }} \times 100$ (Oke et al., 2013)

A one-tailed t-test was used to test the 
Table 2: Susceptibility pattern of test bacteria to HS.

\begin{tabular}{lllllll}
\hline Test organism & \multicolumn{6}{l}{ Zone of inhibition (mm) } \\
\hline & HSM & HDT & HSK & HSF & Positive control & Negative control \\
S. aureus & 12 & 10 & 9 & 5 & 32 & - \\
E. coli & 9 & 6 & 5 & 4 & 30 & - \\
Klebsiella spp. & 9 & 8 & 6 & 4 & 31 & - \\
P. aeruginosa & 9 & 5 & 5 & 4 & 29 & -
\end{tabular}

- No inhibition

significance of the difference between the mean cfu count reductions of the two products.

\section{Results}

As shown in table 2, HSM had the highest inhibitory effect against all the test organisms where it produced the highest zones of inhibition against $S$. aureus $(12.0 \mathrm{~mm})$ and $9.0 \mathrm{~mm}$ against each of E. coli, Klebsiella spp. and P. aeruginosa). HDT followed HSM in terms of effectiveness as it had its highest inhibition against $S$. aureus $(10.0$ $\mathrm{mm}$ ) and its lowest inhibition against $P$. aeruginosa $(5.0 \mathrm{~mm})$; although it produced the same inhibitory effect as HSK $(5.0 \mathrm{~mm})$ against $P$. aeruginosa. The zones of inhibition of HDT against $E$. coli $(6.0 \mathrm{~mm})$ and Klebsiella spp. $(8.0 \mathrm{~mm})$ were higher than those of HSK (5.0 mm and $6.0 \mathrm{~mm}$ respectively). HSF was the least inhibitory against all the test organisms as it produced inhibition zones of 5.0 $\mathrm{mm}$ against $S$. aureus and $4.0 \mathrm{~mm}$ against all the other test organisms. S. aureus was the most susceptible test organism to all the HS with the highest susceptibility being to HSM (12.0 mm) and the lowest was to HSF $(5.0 \mathrm{~mm})$. Conversely, P. aeruginosa was the most resistant organism to all the HS. It displayed maximum susceptibility to HSM $(9.0 \mathrm{~mm})$ and its lowest susceptibility was to HSF $(4.0 \mathrm{~mm})$.

Table 3: Minimum inhibitory concentrations of HS against test organisms.

\begin{tabular}{lllll}
\hline Test organism & \multicolumn{4}{l}{ MIC of hand sanitizer (\%) } \\
\cline { 2 - 5 } & HSM & HDT & HSK & HSF \\
\hline S. aureus & 90 & 95 & 100 & 100 \\
E. coli & 90 & 95 & 95 & 100 \\
K. pneumonia & 90 & 95 & 100 & 100 \\
P. aeruginosa & 95 & 100 & 100 & 100 \\
\hline
\end{tabular}

Table 4: Percentage cfu reduction of viable bacteria from hands of subjects by HSM and HDT

\begin{tabular}{lll}
\hline Subjects & \multicolumn{2}{l}{ \% cfu reduction } \\
\hline & HSM & HDT \\
\cline { 2 - 3 } A & 70 & 60 \\
$B$ & 75 & 65 \\
$C$ & 75 & 60 \\
$D$ & 70 & 65 \\
E & 70 & 60 \\
Mean reduction & 72 & 62 \\
\hline
\end{tabular}


The results of the MIC tests (table 3 ) followed the same pattern as that of the susceptibility test. HSM was the most effective with the lowest MIC value ( $90 \%$ ) recorded in the experiment against all the test bacteria except $P$. aeruginosa against which it had an MIC value of $95 \%$. HSF was the least effective as it had the maximum value of MIC possible (100\%) against all the test organisms. Higher MIC values for an antimicrobial agent is an indication of its poor activity (strain resistance) against the test organism (Levison, 2004).

\section{Discussion}

The relatively higher susceptibility of $S$. aureus to the HS in this study shows that the composition of the products is effective in inhibiting the organism. This is particularly important in the Nigerian setting where S. aureus has been implicated in many cases of nosocomial and community-acquired infections (Ghebremedhin et al., 2009; Shittu et al., 2011). Thus, of all the HS tested in this study, HSM is the most promising for use in the control/prevention of the spread of $S$. aureus infections such as boils, neonatal sepsis and bacteraemia in Nigeria. All HS showed poor activity against $P$. aeruginosa in this study. This is probably due to the decreased outer membrane permeability shown by the bacterium to antimicrobials in addition to its adaptive mechanisms which enable it to evade antibacterial therapy (Hancock and Speert, 2000).

None of the products exhibited bactericidal activity against any of the test organisms as all the agar plates still had visible bacterial growths on them after incubation. This indicated that the HS were only bacteriostatic against the selected test bacteria. Lack of bactericidal activity could be as a result of the loss of the active ingredient by evaporation due to extensive or improper storage. It is also possible that poor adherence to good manufacturing practices and poor quality control during production could have led to the poor activity.

The percentage cfu reductions of HSM and HDT are presented in table 4. HSM had mean cfu reduction of $72 \%$ while that of HDT was $62 \%$. One-tailed t test of the data showed that HSM had significantly higher $\left(\dagger_{(0.05,4)}=2.132\right)$ mean cfu reductions of viable bacteria than HDT, therefore implying that HSM was more effective than HDT.

The highest mean reduction of bacteria by HSM $(72 \%)$ which was the most effective in this study was still less than the $99.99 \%$ claim which appears on many of the products. In a similar study, Oke et al. (2013) found that the highest reduction obtained from some alcohol-based hand sanitizer gels sold in Ilorin, Nigeria, was $89.9 \%$ which was also less than the $99.99 \%$ claim by the manufacturers. None of the sanitizers in the study was bactericidal against the test bacteria. These results suggest that many of the HS products do not contain the required level of alcohol that is sufficient to kill bacteria. Reynolds et al. (2006) reported that a number of products in American stores contained alcohol in concentrations as low as $33 \%$ and $40 \%$ and that the products with $40 \%$ alcohol content produced no significant reductions in cfu while those with up to $62 \%$ alcohol reduced cfu by up to $90 \%$. Of all the HS evaluated in this study, HSM was most effective in inhibiting test bacteria and in reducing mean log cfu of bacteria from the hands of volunteers. This is possibly due to the composition of the product. HSM is the only HS that had two types of alcohols as active ingredients (ethyl alcohol and isopropyl alcohol). Previous studies have demonstrated the efficacy of antibacterial preparations having combinations of alcohols over those with just one alcohol. Marchetti et al. (2003) in their investigation showed that Sterilium, a product containing $45 \%$ 2-propanol and 30\% 1-propanol, had significantly better immediate and residual antimicrobial effect than the reference alcohol which contained $60 \%$ n-propanol only. Similarly, Kramer et al. (2002) found that hand rinse products having combinations of either ethanol, 1-propanol or 2-propanol produced better results in terms of compliance with EN1500 requirements than hand gels with mostly one type of alcohol.

These observations may be due to the 
synergistic effect of the alcohol combinations (Kampf and Kramer, 2004). The effectiveness of alcohol hand sanitizers is influenced by the concentration and type of alcohol present (Michaels et al., 2003). Alcohols exert disinfectant activity in bacteria by causing protein denaturation, disruption of tissue membranes and dissolution of several lipids. More so, isopropyl alcohol, which is present in HSM, is known to be superior to ethanol as an antiseptic (Kar, 2008). The other products had only one alcohol type as the active ingredient. The relatively poor efficacy of the other HS could also be as a result of the negative interactive effects of the non-active ingredients such as fragrance, emollients, humectants and thickening agents which could likely prevent the cidal effect of the products from reaching the target bacteria (Oke et al., 2013).

\section{Conclusion}

This research evaluated the antibacterial efficacy of popular brands of hand sanitizers sold in Nigeria. The products showed varying level of inhibition against the test organisms. S. aureus was the most susceptible to all the products while $P$. aeruginosa was the most resistant. HSM performed best in terms of inhibitory action against the test organisms and in reducing mean log counts of bacteria on the hands of subjects. None of the products was bactericidal and all the HS failed to achieve $99.9 \%$ killing of bacteria as was claimed on their labels. HSM appears to be promising for use in controlling the spread of staphylococcal infections but this would require an improvement on its effectiveness and consistency in its activity based on the composition of its active ingredients.

Our results agree with previous findings which have pointed to the poor effectiveness of many brands of hand sanitizers against common bacteria. The performance of such products is quite far from the claims of the manufacturers. There is a need to verify the concentration of alcohol or any other active ingredients in hand sanitizers before they are approved for sale.
Regulations should be put in place to guide their manufacture and companies that make false claims should be sanctioned. Sellers of such products should on their part store the products according to the manufacturers' recommendations so as to avoid loss of efficacy.

\section{References}

Bischoff, W.E., Reynolds, T.M., Sessler, C.N., Edmond, M.B. and Wenzel, R.P. (2000). Handwashing compliance by health care workers: the impact of introducing an accessible, alcohol-based hand antiseptic. Archives of Internal Medicine, 160(7), 1017-1021.

Bloomfield, S.F., Aiello, A.E., Cookson, B., O'Boyle, C. and Larson, E.L. (2007). The effectiveness of hand hygiene procedures in reducing the risks of infections in home and community settings including handwashing and alcohol-based hand sanitizers. American Journal of Infection Control, 35(10), S27-S64.

Boyce, J.M. and Pittet, D. (2002). Guideline for hand hygiene in health-care settings: recommendations of the Healthcare Infection Control Practices Advisory Committee and the HICPAC/SHEA/APIC/IDSA Hand Hygiene Task Force. Infection Control and Hospital Epidemiology, 23(S12), S3-S40.

Cheesbrough, M. (2006). District laboratory practice in tropical countries, part 2 second edition. Cambridge University Press, New York.

CLSI. (2006). Methods for dilution antimicrobial susceptibility tests for bacteria that grow aerobically; approved standard-seventh edition. Clinical and Laboratory Standards Institute document M7-A7 [ISBN 156238-587-9]. Clinical and Laboratory Standards Institute, 940 West Valley Road, Suite 1400, Wayne, Pennsylvania 19087-1898 USA.

FDA. (2011). Hand sanitizers carry unproven claims to prevent MRSA infections. in: 
FDA Consumer Health Information April 2011, U.S. Food and Drug Administration, pp. 1-2.

Gagne, D., Bedard, G. and Maziade, P. (2010). Systematic patients hand disinfection: impact on meticillin-resistant Staphylococcus aureus infection rates in a community hospital. Journal of Hospital Infection, 75(4), 269-272.

Ghebremedhin, B., Olugbosi, M., Raji, A., Layer, F., Bakare, R., König, B. and König, W. (2009). Emergence of a community-associated methicillin-resistant Staphylococcus aureus strain with a unique resistance profile in Southwest Nigeria. Journal of Clinical Microbiology, 47(9), 2975-2980.

Hancock, R.E. and Speert, D.P. (2000). Antibiotic resistance in Pseudomonas aeruginosa: mechanisms and impact on treatment. Drug Resistance Updates, 3(4), 247-255.

Jumaa, P.A.( 2005). Hand hygiene: simple and complex. International Journal of Infectious Diseases, 9(1), 3-14.

Kampf, G. and Kramer, A. (2004). Epidemiologic background of hand hygiene and evaluation of the most important agents for scrubs and rubs. Clinical Microbiology Reviews, 17(4), 863-93.

Kar, A. (2008). Pharmaceutical microbiology. New Age International (P) Limited, Publishers, New Delhi.

Knittle, M.A., Eitzman, D.V. and Baer, H. (1975). Role of hand contamination of personnel in the epidemiology of gram-negative nosocomial infections. The Journal of Pediatrics, 86(3), 433-437.

Kramer, A., Rudolph, P., Kampf, G. and Pittet, D.( 2002). Limited efficacy of alcohol-based hand gels. The Lancet, 359(9316), 14891490.

Levison, M.E. (2004). Pharmacodynamics of antimicrobial drugs. Infectious Disease Clinics of North America, 18(3), 451-465.

Liu, P., Yuen, Y., Hsiao, H.-M., Jaykus, L.-A. and Moe, C. (2010). Effectiveness of liquid soap and hand sanitizer aaninst Norwalk virus on contaminated hands. Applied and Environmental Microbiology, 76(2), 394399.

Marchetti, M.G., Kampf, G., Finzi, G. and Salvatorelli, G. (2003). Evaluation of the bactericidal effect of five products for surgical hand disinfection according to prEN 12054 and prEN 12791. Journal of Hospital Infection, 54(1), 63-67.

Michaels, B., Gangar, V., Lin, C.M. and Doyle, M. (2003). Use limitations of alcoholic instant hand sanitizer as part of a food service hand hygiene program. Food Service Technology, 3(2), 71-80.

Montravers, P., Lepape, A., Dubreuil, L., Gauzit, R., Pean, Y., Benchimol, D. and Dupont, $H$. (2009). Clinical and microbiological profiles of community-acquired and nosocomial intra-abdominal infections: results of the French prospective, observational EBIIA study. Journal of Antimicrobial Chemotherapy, 63(4), 785794.

Mortimer Jr, E.A., Lipsitz, P.J., Wolinsky, E., Gonzaga, A.J. and Rammelkamp Jr, C.H. (1962). Transmission of staphylococci between newborns: importance of the hands of personnel. Archives of Pediatrics and Adolescent Medicine, 104(3), 289.

Oke, M.A., Bello, A.B., Odebisi, M.B., Ahmed ElImam, A.M. and Kazeem, M.O. (2013). Evaluation of antibacterial efficacy of some alcohol-based hand sanitizers sold in Ilorin (North-Central Nigeria). Ife Journal of Science, 15(1), 111-117.

Reynolds, S.A., Levy, F. and Walker, E.S. (2006). Hand sanitizer alert. Emerging Infectious Diseases, 12(3), 527-529.

Rosenthal, V.D., Maki, D.G., Mehta, A., ÁlvarezMoreno, C., Leblebicioglu, $H$., Higuera, F., Cuellar, L.E., Madani, N., Mitrev, Z. and Dueñas, L. (2008). International nosocomial infection control consortium report, data summary for 2002-2007, issued January 2008. American Journal of Infection Control 36(9) 627-637 
Sakamoto, F., Yamada, H., Suzuki, C., Sugiura, H. and Tokuda, Y. (2010). Increased use of alcohol-based hand sanitizers and successful eradication of methicillinresistant Staphylococcus aureus from a neonatal intensive care unit: $A$ multivariate time series analysis. American Journal of Infection Control, 38(7), 529534.

Sheehan, J.J., Mott, P.J., Sisk, B.W., Arbogast, J.W., Ferrazzano-Yaussy, $C$. and Bondi, C.A. (2007). Alcohol-based instant hand sanitizer use in military settings-a prospective cohort study of army basic trainees. Military Medicine, 172(11), 11701176.

Shittu, A., Okon, K., Adesida, S., Oyedara, O., Witte, W., Strommenger, B., Layer, F. and Nübel, U. (2011). Antibiotic resistance and molecular epidemiology of Staphylococcus aureus in Nigeria. BMC Microbiology, 11(1), 92.
Talaat, M., Afifi, S., Dueger, E., El-Ashry, N., Marfin, A., Kandeel, A., Mohareb, E. and El-Sayed, N. (2011). Effects of hand hygiene campaigns on incidence of laboratory-confirmed influenza and absenteeism in school children, Cairo, Egypt. Emerging Infectious Diseases, 17(4), 619.

Valgas, C., Souza, S.M.d., Smânia, E.F. and Smânia $\mathrm{Jr}$, A. (2007). Screening methods to determine antibacterial activity of natural products. Brazilian Journal of Microbiology, 38(2), 369-380.

WHO. (2006). WHO guidelines on hand hygiene in health care (advanced draft) : global safety challenge 2005-2006: clean care is safer care. World Health Organization, Geneva 